\title{
Three-dimensional seismic tomography of the lower crust and mantle along Lau back-arc spreading centers
}

\author{
D. EASON* AND R. DUNN
}

Department of Earth Sciences, University of Hawai'i at Mānoa, 1680 East-West Rd, Honolulu, HI 96822

(*correspondence: deborahe@hawaii.edu)

Spreading centers in the Lau back-arc basin exhibit significant changes in the style of seafloor volcanism, crustal structure, and lava composition based on their proximity to the active arc. The L-SCAN active source seismic tomography experiment along the Eastern Lau Spreading Center identified a change in crustal thickness and structure close to the arc, with corresponding changes in the shallow magmatic system beneath the spreading center $[1,2]$. To investigate deeper portions of the magmatic system, lower crust and mantle, we have extended the previous tomographic imaging to include all primary crustal P-wave arrivals, mantle refraction arrivals $(\mathrm{Pn})$, and Moho reflection arrivals $(\mathrm{PmP})$, incorporating $>500,000$ travel time picks into the tomographic analysis. Preliminary results indicate significant variations in Moho depth $(<6.0-8.4 \mathrm{~km})$, with the thinnest crust found along the ridge axis at spreading center segments located far from the arc. The thickest crust appears to be generated at spreading centers located close to the arc, where subduction-derived water strongly influences melt production and composition. Low velocity anomalies associated with the magmatic system beneath the spreading center extend into the lower crust and upper mantle, but are generally lower amplitude and less continuous than in the upper crust. In addition, these low velocity anomalies are deeper and broader on average for ridge segments located far from the arc, while the near-arc low velocity zone appears to be narrower and more strongly expressed at shallow depths. These variations in the seismically-imaged magmatic system correlate with changes in lava composition, magma differentiation processes (based on petrologic modeling), and variations in eruptive style and ridge morphology along-axis. Results indicate that slab-derived water entrained in the near-arc ridge system not only enhances mantle melting, as commonly proposed to explain high crustal production in back-arc environments, but also affects magma storage, differentiation, and crustal accretion processes.

[1] Arai \& Dunn (2014) EPSL 390, 304-317. [2] Dunn et al. (2013) EPSL 371-372, 112-124. 